$\overline{\text { ReVIEW ARTicle }}$

\title{
FORM-MEANING INTERACTION IN DIACHRONY: A CASE STUDY FROM JAPANESE
}

\author{
KAORU HORIE \\ Tohoku University*
}

The Evolution of Grammar: Tense, Aspect and Modality in the Languages of the World, by Joan Bybee, Revere Perkins, and William Pagliuca, The University of Chicago Press, 1994, xxii +398 pp.

\section{Introduction}

The 1990s has seen a greater convergence of interest in Cognitive and Functional-Typological Linguistics as represented by the 1995 Linguistic Institute in New Mexico and the two concurrent conferences, i.e. International Cognitive Linguistics Association and Functional Approaches to Grammar. ${ }^{1}$ One of the traditional topics in Historical Linguistics which has received renewed interest due to this intellectual trend is Grammaticalization (or Grammaticization) as evidenced by several major publications exclusively devoted to this topic, i.e. Traugott and Heine (1991), Heine, Claudi and Hünnemeyer (1991), and Hopper and Traugott (1993). ${ }^{2}$

Grammaticalization refers to a diachronic process whereby a lexical word becomes a function word such as tense-aspect-modality marker, auxiliary, conjunction or complementizer. The following examples

* I would like to thank Dale Andrews, Debra Occhi, Yasuhiro Shirai, Foong-ha Yap, and two anonymous reviewers for their insightful comments on the earlier version of this paper. I also benefitted from discussion with Hiromu Kato, Kei Yoshimoto, and Dai Sato. The usual disclaimer applies.

1 Readers are referred to Horie (1995) for the information on recent literature on linguistic typology.

2 Matsumoto (1995a) presents a brief survey of recent literature on grammaticalization. 
from Hopper and Traugott (1993: 105) illustrate a typical functional shift which accompanies grammaticalization:

(1) Carefully considering/Having carefully considered all the evidence, the panel delivered its verdict.

(2) Considering (*having carefully considered) you are so short, your skill at basketball is unexpected.

In (1), consider still functions as a verb with lexical meaning as demonstrated by its grammatical behavior (i.e. possibility of adverbial modification and tense inflection, dependence of the subject interpretation on the matrix clause). In (2), in contrast, consider loses some verbal characteristics and functions as a conjunction.

As noted by Hopper and Traugott (1993:1), the term "grammaticalization" also refers to "the study of language that focuses on how grammatical forms and constructions arise, how they are used, and how they shape the language." Grammaticalization as a subfield of linguistics is thus indispensable to linguistic theories in general and theories on language change in particular, because it offers insight into the mechanism and directionality of the process whereby a language constructs grammatical structure on the basis of lexical resources at its disposal. ${ }^{3}$

The Evolution of Grammar (henceforth abbreviated as EOG) by Bybee, Perkins and Pagliuca has now joined this growing body of research on grammaticalization. EOG is a cross-linguistic study of grammaticalization of Tense-Aspect-Modality expressions, or what they call Tense-Aspect-Modality "grams." EOG consists of the following eight chapters. Chapter 1 "Theoretical Background" gives a brief exposition of the notion of grammaticalization and presents a set of hypotheses to be tested in EOG, e.g. source determination, unidirectionality, universal paths, and retention of meaning. Chapter 2 "Method Used in the Study" explains the procedure of constructing a stratified probability sample of languages and selecting reference materials, as well as the criteria by which to select forms to code them as well as their meaning. Chapter 3 "Anterior, Perfective and Related Senses" examines the lexical sources and paths of development leading to Pasts and Perfectives, along which are located such related

3 Readers are referred to Hopper and Traugott (1993), Chapter 2, for a brief historical survey of earlier and more recent research on grammaticalization. 
grammatical meanings as Completives, Anteriors and Resultatives. Chapter 4 "A Quantitative Approach to Grammaticization" proposes a quantitative test of one of the most important hypotheses to be tested in EOG, i.e. parallel reduction hypothesis, on the basis of three clustered measures of grammaticalization of form and the correlated semantic measures of grammaticalization. Chapter 5 "Progressive, Imperfective, Present," similarly to Chapter 3, examines the lexical sources and paths of development leading to Presents, Imperfectives and Progressives, along which are found such related grammatical meanings as Habitual, Iterative, Continuative and Frequentative. Chapter 6 "Mood and Modality" aims at establishing the major paths of development for Mood and Modality notions with attention to the question of how and why particular grammatical meanings arise in a particular domain of Modality. Chapter 7 "Future" examines the developmental pathways to this cross-linguistically important tense category with modal meaning. Chapter 8 "Mechanisms of Semantic Change" discusses five mechanisms of semantic change for which crosslinguistic evidence was presented in Chapters 3, 5, 6 and 7, i.e. Metaphorical Extension, Inference, Generalization, Harmony, and Absorption of Contextual Meaning. The eight chapters are followed by Appendix A "GRAMCATS Sampling Procedure," Appendix B "Meaning Labels," Appendix C "Sources of Language Data," Bibliography for GRAMCATS Sample, References, Author Index, and Subject Index.

The organization of this review article is as follows. Section 1 highlights the two important features of EOG, i.e. cross-linguistic and quantitative orientations. Section 2 critically examines a selection of hypotheses proposed in EOG relative to patterns of grammaticalization of Tense-Aspect grams observed in Japanese. Section 3 tests the paths of development of Modality grams proposed in EOG in light of data on Modality grams in Japanese. Section 4 argues for the importance of studying Japanese grammar from the perspective of grammaticalization espoused in EOG. Section 5 summarizes the article.

\section{Cross-linguistic and Quantitative Orientations of EOG}

EOG has two distinguishing features not shared by many previous studies on grammaticalization, i.e. cross-linguistic and quantitative orientations. Studies on grammaticalization have tended to focus on a 
single language or a limited set of languages (e.g. Heine, Claudi and Hünnemeyer (1991)'s focus on African languages) because of the difficulty in obtaining reliable information on the diachronic change of a diverse range of languages from published materials. EOG has overcome this difficulty by constructing a database called GRAMCATS from published reference grammars of seventy-six languages, which are controlled for genetic and areal biases. ${ }^{4}$ The authors concede that the reference grammars did not always provide sufficient information to identify the meaning/function of a given grammatical form which was the target of their investigation (e.g. EOG: 35-36). Nevertheless, the cross-linguistically recurrent patterns of grammaticalization observed in the languages of the world and catalogued in this book are convincing enough to demonstrate that grammaticalization is a phenomenon universally observable across genetic groupings and areal boundaries.

The second feature of this book, i.e. quantitative orientation, is no less important. Grammaticalization theory has a home-grown set of hypotheses shared by most of its practioners. For instance, it is generally assumed that grammatical meaning, which is relatively abstract, evolves out of lexical meaning, which is more specific. It is also generally agreed that there is an increase in morphosyntactic boundedness of a grammatical form as the degree of its grammaticalization proceeds. However, such metatheoretical assumptions, usually followed by a few illustrative examples, have never been rigorously tested in statistical terms.

The authors of EOG thus set themselves a challenging task of testing a set of hypotheses of grammaticalization in quantitative terms. In order to achieve this objective, they collected information on the meaning and phonetic shape of the grams expressing Tense, Aspect and Modality from seventy-six languages, presented in Appendix C "Sources of Language Data." 5 The information on the meaning of a

4 Readers are referred to Dryer (1989), Perkins (1989), and Rikhoff, Bakker, Hengeveld and Kahrel (1993) for discussions of problems and methods of language sampling in typologically oriented research.

5 Constructing a stratified sample of seventy-six languages in itself is admittedly no easy task, especially in the light of the difficulty of obtaining semantic information from published reference materials. However, as pointed out by an anonymous reviewer, it must be noted that the EOG's sample is much smaller than the samples used in other typologically oriented works such as Dryer (1992) and Nichols (1992), which used a sample of 625 languages and 174 languages respectively. 
gram is important in determining which stage of grammaticalization it is undergoing, e.g. whether a particular gram encodes earlier Anterior stage or later Perfective stage.

No less crucial is the information on the phonetic shape of a gram, on the basis of which the degree of phonetic reduction is quantitatively measured in EOG. The three quantifiable indicators of phonetic reduction thus arrived at in EOG are "shortness" (i.e. "the number of consonants and vowels present in the gram," EOG: 108), "dependence" (i.e. "the general loss of autonomy," EOG: 110), and "fusion" (i.e. "the actual fusion of the gram with the verb," EOG: 110).

As a result of synthesizing this semantic information and phonetic information obtained, the authors have been able to present a significant statistical confirmation of the hypothesis that "semantic reduction is paralleled by phonetic reduction" (EOG: 19) in grammaticalization process, i.e. what EOG calls "parallel reduction hypothesis."

Previously many functionally oriented linguists presented a strong case for the intimate relationship which holds between meaning and form of linguistic forms from a primarily synchronic perspective, e.g. Bolinger's “one form, one meaning" principle (Bolinger (1977)), Haiman's “iconic motivation” (Haiman (1983, 1985)), and Givón's "binding hierarchy" (Givón (1980, 1990)). EOG's statistical confirmation of the "parallel reduction hypothesis" has considerably enhanced the previous researchers' arguments by presenting a strong case for close form-meaning correlation (or co-reduction) in diachronic change. ${ }^{6}$

In the following section, I will critically examine a selection of the hypotheses tested in EOG in the light of the data on Tense and Aspect grams from Japanese.

2. Examination of a Selection of Hypotheses Tested in EOG: A Case Study from Japanese

EOG has amassed cross-linguistic data on Tense-Aspect grams in

6 EOG's contribution to the area of research on form-meaning interaction is comparable to that of Hawkins (1994), which presents a processing-oriented quantifiable principle of linear ordering, to the area of research on word order universals. 
Chapters 3 and 5 and convincingly demonstrated that similar grammaticalization paths and patterns can be observed in a wide range of languages. Chapter 3 discusses Completive, Anterior, Perfective and Past grams, whereas Chapter 5 discusses Progressive, Imperfective and Present grams.

In this section, I will critically examine two important hypotheses discussed and tested in EOG in relation to Tense-Aspect grams, i.e. "source determination" and "parallel reduction," in the light of the data on Tense-Aspect grams in Japanese. Due to space limitations, I will limit my discussion to the domains of Completive, Anterior, Perfective and Past grams.

EOG proposes five different stages of "semantic age" for grams that belong to the Completive, Anterior, Perfective and Past pathway. These stages are referred to as "perfages," and are arranged from perfage 1 , the youngest semantic age, to perfage 5 , the oldest semantic age, in the following Figure (constructed on the basis of the information given in EOG: 105):

Perfage $1>$ Perfage $2>$ Perfage $3>$ Perfage $4>$ Perfage 5

Completives Young Anteriors Old Anteriors Perfectives Simple Pasts

Figure 1. Five Different Stages along the Completive, Anterior, Perfective, and Past Pathway ${ }^{7}$

For instance, comparing English Anterior and Simple Past enables us to appreciate the differing degrees of grammaticalization between the given two stages. Consider the following examples:

(3) a. Carol has taken statistics. (EOG: 61)

b. ?Carol has taken statistics last semester. (EOG: 62)

c. Carol took statistics (last semester).

English Anterior, which is constructed periphrastically, indicates a past event which has relevance to the present, as in (3a), but unlike Simple Past, it does not normally refer to a specific past event, as shown in (3b). In contrast, Simple Past, which is encoded as being closely affixed to and fused with the matrix verb, can refer to a specific or nonspecific past event, as shown in (3c). Importantly, the greater

${ }^{7} X>Y$ in Figure 1 should be read as $X$ is older than $Y$ and does not necessarily entail that $\mathrm{X}$ always evolves into $\mathrm{Y}$, because EOG does not have "documented cases of perfective evolving into simple past" (EOG: 105). 
semantic specificity of English Anterior is paralleled by its lesser degree of formal reduction, which presents a striking contrast to the greater semantic generality and concomitant greater formal reduction of English Simple Past.

Modern Japanese has a relatively rich inventory of grams in the area of Aspect. Teramura (1984) gives a three-level classification of Aspect, i.e. Primary Aspect ("Ichijiteki Asupekuto"), Secondary Aspect ("Nijiteki Asupekuto"), and Tertiary Aspect ("Sanjiteki Asupekuto"). The following Figure is constructed on the basis of the information given in Teramura (1984: 119-183):

Primary Aspect: $-r u,-t a$

Secondary Aspect: -te iru, -te aru, -te shimau, -te kuru, -te iku

Tertiary Aspect: -hajimeru, -tsuzukeru, -owaru, -kakaru, -tsukusu, etc.

Figure 2. Teramura (1984)'s Three-level Classification of Aspect Grams in Modern Japanese

Teramura (1984: 118) notes that Primary Aspect (i.e. Imperfective $-r u$ and Perfective $-t a$ ) is a full-fledged grammatical category, whereas Secondary and Tertiary grams are the lexical verbs which have become grammaticalized through the process of loss or bleaching of original lexical meaning and grammatical properties. ${ }^{8}$ Furthermore, Teramura notes that Secondary Aspect grams are a closed class whose members are relatively general in grammatical meaning (e.g. -te shimau encoding Anterior, Completive and Perfective), whereas Tertiary Aspect grams are a rather heterogeneous class whose members, some of which cooccur with a very limited number of main verbs, differ considerably in terms of the degree of grammaticalization and tend to encode rather specific grammatical meanings (e.g. -tsukusu encoding Completive only).

Teramura claims that grammaticalization takes place as indicated in the following Figure (cf. Teramura (1984: 118)):

8 It must be noted that Teramura does not use the word "grammaticalization" or its Japanese equivalent "bunpooka" in his work. However, as I discuss later in Section 4, Japanese grammarians such as Teramura and Akira Mikami have recognized the historical process wherein a lexical word becomes grammatical through the loss or bleaching of lexical meaning, calling it "keishikika" (lit. formalization). 
Primary Aspect grams $>$ Secondary Aspect grams $>$ Tertiary Aspect grams

most grammaticalized

least grammaticalized

Figure 3. Grammaticalization of Aspect Grams in Modern Japanese

A full-scale exploration into the Aspect grams in Japanese has not yet been attempted from the perspective of grammaticalization; it is a potentially very intriguing area of research which deserves further study. However, due to space limitations, I will limit myself to a subset of the Aspect grams, i.e. - $t a$, which encodes Anterior, Perfective as well as Past Tense, -te iru, which encodes Resultative, Anterior, and Progressive, and -te shimau, which encodes Completive, Anterior and Perfective.

The following Figure summarizes EOG's definitions of five Perfective-related Aspect and Tense grams:

Resultatives: "a state exists as a result of a past action", "are compatible with the adverb 'still' and and are used only with telic verbs, that is, verbs which describe events which have inherent endpoints" (EOG: 54)

Anteriors (or "Perfects"): "signals that the situation occurs prior to reference time, and is relevant to the situation at reference time" (EOG: 54 )

Completive: "to do something thoroughly and to completion, as is expressed, for example, in 'to shoot someone dead' or 'to eat up" " (EOG: 54)

Perfective: "the situation is viewed as bounded temporarily; cannot be simultaneous with the moment of speech; in the non-past it is sometimes interpreted as future" (EOG: 317 )

(Simple) Past: "indicates a situation which occurred before the moment of speech" (EOG: 55)

Figure 4. EOG's Definitions of Perfective-related Aspect and Tense Grams

Each of the three Japanese grams in question encodes a slightly different range of grammatical meanings defined in Figure 4. First of all, -ta encodes Anterior, Perfective and Past: 
(4) Densha-ga choodo ki-ta. ${ }^{9}$

train-Nom just come-TA

'The train has just arrived.' (Anterior)

(5) Shiai-ga yooyaku owat-ta. game-Nom finally end-TA

'The game has finally ended.' (Perfective)

(6) Daitooryoo-wa sannen maeni nihon-ni ki-ta.

president-Top three years before Japan-to come-TA

'The president came to Japan three years ago.' (Simple Past)

-Te iru encodes Resultative, Anterior, and Progressive Aspect. Since Progressive Aspect is not relevant to our discussion, only Resultative and Anterior uses are illustrated:

(7) Ano hito-wa mada okotte iru.

that person-Top still get angry-TE IRU

'That person is still angry.' (Resultative)

(8) Sono otoko-ni-wa sankai atte iru.

that-man-to-Top three times meet-TE IRU

'(I) have met the man three times.' (Anterior)

Finally, -te shimau encodes Anterior, Completive and Perfective: ${ }^{10}$

(9) Ano hito-wa amerika-ni itte shimatta.

that person-Top America-to go-TE SHIMAU

'That person has gone to America (and is no longer here).' (Anterior)

(10) Asu madeni kono hon-o yonde shimai nasai. tomorrow by this book-Acc read-TE SHIMAU do:Imp '(I order you to) finish reading this book by tomorrow.' (Completive/Perfective)

The primary reasons for choosing these three grams are: (i) they are sufficiently general in grammatical meaning (as compared to more specific Secondary Aspect grams -te aru, -te kuru, -te iku and even

9 The following abbreviations are used in the gloss: Acc (Accusative Marker), Gen (Genitive Marker), Ger (Gerundive Form), Imp (Imperative Marker), Neg (Negative Marker), Nom (Nominative Marker), Past (Past Tense Marker), Quot (Quotative Marker), Top (Topic Marker).

10 Ono (1992) presents a possible grammaticalization scenario of te shimau based on the synchronic data. However, Ono does not discuss Perfective and Completive uses of -te shimau, focusing instead on "Perfect" (EOG's Anterior), "Frustrative," and "Non-volitional/evidential" uses. 
more specific Tertiary Aspect grams) and each of them covers a different combination of Aspect or Tense-Aspect functions, and (ii) very importantly for our current inquiry, each seems to display a different degree of grammaticalization, thereby enabling us to test some of the hypotheses tested in EOG.

In the remainder of this section, I will examine two important hypotheses tested in EOG, i.e. "source determination" and "parallel reduction," in the light of the three Tense and Aspect grams in Modern Japanese.

2.1. Source Determination and Parallel Reduction as Reflected in Japanese Tense-Aspect Grams

EOG presents the hypothesis that "the actual meaning of the construction that enters into grammaticalization uniquely determines the path that grammaticalization follows and, consequently, the resulting grammatical meanings" (EOG: 9). In the domains of Perfectiverelated Aspect and Past grams, EOG has explored the following possible paths of development (constructed on the basis of the information given in Figure 3.1, EOG: 105):

(a) 'be/have' $>$ Resultative $>$ Anterior $>$ Perfective/Simple Past

(b) 'finish' $>$ Completive $>$ Anterior $>$ Perfective/Simple Past

(c) 'finish' $>$ Completive $>$ Derivational Perfective

(d) 'come' $>$ Anterior $>$ Perfective/Simple Past

Figure 5. Grammaticalization Paths of Perfective-related Aspect and Past Tense Grams

The grammaticalization paths undergone by the three Japanese grams, i.e. -ta, -te iru, and -te shimau, accurately fit in with EOG's hypothesis of source determining the grammaticalization paths.

Perfective and Past gram - $t a$ evolves from Old Japanese Resultative/Anterior gram -tari, which originated as a combination of conjunctive particle -te and existential verb ari (Matsumura (1969: 129, 142)). Its development is thus correctly captured by the path (a) in Figure 5 above.

Resultative and Anterior gram -te iru is on the same developmental path (a) as -ta. Its lexical origin is even more transparent than -ta in that its component iru still functions as a matrix animate existential 
verb in Modern Japanese. Unlike -ta, however, -te iru hasn't evolved into a Perfective or Past gram yet. ${ }^{11}$

Finally, -te shimau, which includes a lexical verb shimau meaning "finish, put (something) away," appears to be on the developmental path (b), rather than (c), considering the range of aspectual meanings it has, i.e. Completive, Anterior and Perfective. Needless to say, however, the exact developmental path of shimau must be supported by historical documents.

The three Tense-Aspect grams also lend empirical support to EOG's "parallel reduction hypothesis," which states that "parallel to the growing phonological dependence on surrounding material is a growing semantic dependence on surrounding material" (EOG: 7), or to put it shortly, that "semantic reduction is paralleled by phonetic reduction" (EOG: 19).

As discussed above, - $t a$ is at the most advanced stage of grammaticalization among the three grams in question as it is the only gram which encodes Simple Past, which is assigned Perfage 5 in Figure 1 above. $-T a$ encodes the most general meaning of the three grams, covering Anterior, Perfective and Past. Importantly, its semantic reduction (reduction of semantic specificity) is paralleled by its phonetic reduction (schematically represented as te ari $>$-tari $>-t a$ ) and dependence on the surrounding material, thereby confirming EOG's parallel reduction hypothesis.

In contrast, both -te iru and -te shimau, though respectively contracted as -teru and -chau in colloquial speech, have not yet shown so much semantic reduction as to advance on their developmental paths to encode Simple Past, unlike a full-fledged Simple Past gram $-t a .^{12}$

In this section, we have been able to confirm that EOG's hypotheses, i.e. source determination and parallel reduction, make overall correct predictions about the development of a subset of Tense and Aspect grams in Japanese. In the following section, we will inquire whether EOG's discussion of Modality grams is directly applicable to the Japanese data.

11 Cf. Yamashita (1996) for a historical development of Resultative and Anterior grams -te iru and -te aru after Medieval Japanese.

12 The analysis of -te iru and -te shimau in this paragraph owes much to discussions with Debra Occhi, Yasuhiro Shirai and Foong-ha Yap. 
3. Remarks on EOG's Treatment of Modality Grams: A Perspective from Japanese

EOG discusses Mood and Modality in Chapter 6 and argues for general paths of development for Modalities such as the following: ${ }^{13}$

(11) Agent-oriented modalities $>$ Speaker-oriented modalities

(12) Agent-oriented modalities $>$ Epistemic modalities

Examples of more specific paths of development of Modalities are given as follows:

(13) ability $>$ root possibility $>$ epistemic possibility

(14) obligation $>$ intention $>$ future

(15) desire $>$ intention $>$ future

Compared to the convincing case made in favor of universal paths of development for Tense and Aspect grams given in Chapters 3 and 5, the proposed universal paths of development for Modalities presented in Chapter 6 are not entirely convincing in the light of the development of Modality grams in Japanese.

One of the implicit assumptions underlying the hypothesized paths of development such as (11) and (12) seems to be the parallelism between different domains of Modalities, e.g. Agent-oriented Modality (e.g. ability, obligation, desire) and Epistemic Modality (e.g. possibility, probability, certainty), or Agent-oriented Modality and Speakeroriented Modality (the modalities which are linguistically encoded by such moods as imperative, prohibitive, hortative). The parallelism between Agent-oriented Modality (traditionally referred to as Deontic Modality) and Epistemic Modality is synchronically observable in languages such as Modern English, where many non-periphrastic modal auxiliaries encode both Modalities (e.g. may, can, should, must).

However, such parallelism is not necessarily obvious in Modern Japanese, which appears to have rather different Modality grams in two domains, as shown below: ${ }^{14}$

13 It should be noted that only a selection of paths of development are discussed here and readers are referred to Figures $6.3-6.6$ on pages $240-241$ of EOG for the complete illustration of general and specific paths of development for Modalities.

14 "Modality" and its linguistic expressions have recently received much attention in Japanese linguistics in Japan (e.g. Nitta and Masuoka (1989), Masuoka (1991), Nitta (1991)), which has a long-standing academic tradition in the studies of socalled "chinjutsu," i.e. speaker's expression of his/her subjective stance as encoded either overtly or non-overtly in a sentence. Readers are referred to Onoe (1996) 
Agent-oriented Modality grams -(rar)eru, -koto-ga dekiru (Ability), -nakereba naranai, -beki da (Obligation), -te mo ii (Permission), -tai, -te hoshii (Desire) etc.

Epistemic Modality grams -ka mo shirenai (Possibility), -rashii, -yooda, -da roo (Probability), -ni chigai nai, -hazu da (Certainty), -sooda (Conjecture or Hearsay) etc.

Figure 6. Agent-oriented and Epistemic Modality Grams in Modern Japanese

As far as Modern Japanese is concerned, there appears to be very little connection between the two types of Modality grams such that Epistemic Modality gram X (e.g. Epistemic Possibility) originally encoded Agent-oriented Modality (e.g. Ability), thereby making it very difficult to test EOG's proposed paths of development of Modality grams such as (11) and (12).

It may be objected that Old (Heian) Japanese had a more intimate connection between the two types of Modalities, as shown below:

Agent-oriented Modality Grams

-ru/raru (Ability), -beshi*15 (Obligation, Intention), - $m u^{*}$ (Intention), -mashi* (Wish), -tashi, -mahoshi (Desire) etc.

Epistemic Modality Grams -beshi* (Certainty), -mu* (Probability), -mashi* (Counterfactual conjecture), -rashi (Certainty), -ramu (Probability, Conjecture on current state-of-affairs) etc.

Figure 7. Agent-oriented and Epistemic Modality Grams in Old (Heian) Japanese

Indeed, Old Japanese had a handful of grams such as -beshi, $-m u$, and -mashi which encode both Agent-oriented and Epistemic

for a historical overview and assessment of studies on "chinjutsu" in Japan. Onoe (1996) notes that the notion of Modality has been extended within some schools of Japanese linguistics beyond the original sense used in Western linguistic tradition, having been applied to a variety of linguistic indicators of speaker's subjective stance, such as sentence-final particles.

15 Asterisks in Figure 7 indicate that the gram in question occurs in both domains of Modality. 
Modalities (in addition, Speaker-oriented Modality as well), reminiscent of English modal auxiliaries such as should. However, unlike English and a number of languages documented in EOG, it seems to be very difficult to prove beyond reasonable doubt that these Old Japanese Modality grams evolve from one domain to another as both Agent-oriented and Epistemic senses (e.g. Obligation and Certainty senses of -beshi) appear to have been present early on (cf. Ono, Satake and Maeda (1990)).

Also it appears to be remarkable that most of Old Japanese Modality grams did not survive into Modern Japanese, except in a few instances such as -beki $d a^{16}(<-$-beshi) and -tai $(<-$ tashi $)$, as can be seen by comparing Figures 6 and 7.

These circumstances surrounding the development of Modality grams in Japanese make it very difficult to confirm general paths of development of Modality grams proposed in EOG, unlike Tense-Aspect grams in Japanese, which were shown to yield strong support to the hypotheses presented in EOG in the previous section. This striking contrast between Tense-Aspect grams and Modality-grams in terms of the degree of verifiability of EOG's hypotheses suggests the possibility that the historical development of Modality grams is more variable across languages than Tense-Aspect grams. In other words, Tense-Aspect grams are universally more constant in terms of historical development than Modality grams, which display greater cross-linguistic variability.

It is also possible that there are other paths of development of Modality grams not explored in EOG. In this connection, I would like to draw attention to the development of auxiliary -oo/-yoo (phonologically conditioned variants), which in Modern Japanese primarily encode a type of Speaker-oriented Modality, i.e. Speaker's Intention or Hortative (Speaker's encouragement of someone else's action). The following examples illustrate the typical uses of -oo/yoo in Modern

16 Beki-da, which in Modern Japanese encodes Agent-oriented Modality of Obligation, is particularly interesting from a historical point of view, because it evolves from Old Japanese besi, which encoded both Obligation (Agent-oriented Modality) and Certainty (Epistemic Modality). It presents a striking contrast to English should, which, according to EOG (p. 200), developed Probability (Epistemic Modality) meaning from the original Obligation (Agent-oriented Modality) meaning. 
Japanese:

(16) Sonnani iya nara, boku-ga yar-oo.

so much hateful if I-Nom do-OO

'If (you) don't like (to do it) so much, I'll do (it).'

(17) Toshokan-de isshoni benkyoo shi-yoo.

library-at together study do-YOO

'Let's study together at the library.'

However, as pointed out by Toyama (1959), -oo/-yoo in early Modern Japanese also encoded a type of Epistemic Modality, i.e. Epistemic Probability. This sense of -oo/-yoo, which has been replaced by more periphrastic auxiliaries such as -daroo and -rashii in matrix sentence, survives into Modern Japanese in some literarysounding embedded constructions:
Ame-ga hur-oo ga,
huru-mai
rain-Nom fall-OO even if fall-Neg Conjecture
ga, watashi-wa iku.

$$
\text { I-Top go }
$$

'I'll go whether it may rain or not.'
Ano hito-ga sonna koto-o shi-yoo to-wa
that person-Nom such thing-Acc do-YOO Quot-Top omowa-nakatta.
think-Neg:Past
'I didn't think that the person would do such a thing.'

Furthermore, as noted by Hotta (1969), it is commonly assumed that -oolyoo derived from Old Japanese auxiliary $-m u$, which encoded Agent-oriented Modality (e.g. Intention), Speaker-oriented Modality (e.g. Hortative), and Epistemic Modality (e.g. Probability). The development from Old Japanese - $m u$ to Modern Japanese -ool-yoo seems to suggest the following complex developmental path of Modality gram not explored in EOG:

(20)
Agent-oriented/Speaker-oriented/Epistemic modalities (Old Japanese) $>$ Speaker-oriented/Epistemic modalities (early Modern Japanese) $>$ Speaker-oriented modality (Modern Japanese) $)^{17}$

This developmental path is supported by the well-established

17 The author acknowledges indebtedness to insightful comments from a reviewer, which led to the rethinking and radical revision of the developmental path proposed in the earlier draft of this paper. 
Semantic-pragmatic Tendency proposed by Traugott and König (1991: 209):

(21) "Meanings tend to become increasingly situated in the speaker's subjective belief-state/attitude toward the situation."

In this section, we have critically examined EOG's proposed paths of development for Modality grams in the light of the data on Japanese. The Japanese data did not clearly lend support to EOG's proposed paths of development for Modality grams, contrary to the rather striking confirmation of EOG's hypotheses for developmental paths of Tense-Aspect grams in section 2. The Japanese data also suggest that there could be greater cross-linguistic variation in the development of Modality grams than in the development of Tense-Aspect grams, and that other paths of development not explored in EOG might present themselves if a wider range of languages are investigated.

\section{How Can EOG Contribute to the Study of Japanese Grammar?}

In this section, I argue for the importance of viewing Japanese language from the perspective of grammaticalization explored in EOG by pointing out some potentially interesting research topics in the grammar of Japanese.

In Section 4.4 "Morphological Typology," EOG advocates revisiting a typology of grammatical meaning proposed by Sapir (1921) and makes the following insightful remark on the possible correlation between a morphological typology of languages and the degree of grammaticalization observable in the languages:

"If morphological typology also involves a typology of grammatical meaning, then we would expect a correspondence between the type of meaning expressed grammatically and the overall formal type of language. Let us call all the grams on the perfective and past path perf grams. Isolating languages would have perf grams with low perfages, namely completives and anteriors, while inflectional languages would have perf grams with high semantic ages, namely perfectives and pasts" (EOG: 116, emphasis added).

The above remark claims that the degree of grammaticalization of grams tends to be greater in inflectional languages than in isolating languages, and leads us to infer that agglutinating languages such as 
Japanese show an intermediate degree of grammaticalization. ${ }^{18}$ In fact, as observed in Section 2 in the discussion of Aspect grams -te iru and -te shimau, Japanese has numerous grams in the various parts of its grammar whose lexical origins are either transparent or relatively easy to arrive at.

Nevertheless, it seems that traditional Japanese grammarians have not recognized the important role played by grammaticalization in affecting the grammatical structure of the Japanese language. Notable exceptions are grammarians such as Akira Mikami and Hideo Teramura, who recognized the notion of grammaticalization under the name of "keishikika" (lit. formalization). For instance, Mikami (1972) defines the term "keishikika" as follows:

"Aru tango ga kan'yoo no kekka, ippootekina yoohoo ni koteishite gengi kara mo sore, toki ni wa hinshi kuzure mo hikiokosu to iu yoo na baai ni sono tango wa keishikika shita to iu." (When a word, as a result of increase in frequency of use, becomes fossilized in usage and deviant from its original meaning, sometimes leading to its decategorization, the word can be recognized as having become formalized; Mikami 1972: 194, emphasis added, translation by KH)

The following are some of the examples of "formalization" cited by Mikami (1972: 197-198, translation and gloss provided by KH):

(22) a. Hon-o makuramoto-ni oite, yomu. book-Acc pillowside-at put:Ger read

'Putting the book at (his) pillowside, (he) reads it.'

b. Hon-o makuramoto-ni oite yomu. book-Acc pillowside-at read ' $(\mathrm{He})$ reads the book at (his) pillowside.'

(23) a. Hana-o motte, byooshitsu-o otonau. flower-Acc bring:Ger hospital room-Acc visit 'Bringing a flower, (he) visits a hospital room.'

b. Hana-o motte byoonin-o nagusameru. flower-with patient-Acc cheer up ' $(\mathrm{He})$ cheers up the patient with a flower.'

In the (a) examples of (22) and (23), the italicized gerundive forms

18 It must be noted that, as Shibatani (1984) points out, the degree of "agglutination" can vary among so-called agglutinating languages such as Japanese, Korean and Turkish. 
of verbs, oite and motte, function as verbs. In contrast, in the (b) examples, the verbs become grammaticalized and function as postpositions together with co-occurring case particles. In each of the (b) examples, the original lexical verb thus has lost its original lexical meaning and encodes grammatical meaning of location or instrument.

As observed in the above examples and in the case of Aspect grams -te iru and -te shimau in Section 2, the process of grammaticalization of lexical verbs into grams is very commonly observed in Japanese. Importantly, the grammaticalized verbs feed into various grammatical categories and become part of the grammar of Japanese. The following figure, constructed largely on the basis of the information given in Mikami (1972: 194-198), shows the extent of this phenomenon:

Adverb: tatoeba ('for example' < tatou 'compare' + Conditional particle $b a$ ), etc.

Aspect gram: cf. Section 2

Complementizer: -to iu (Complementizer modifying NP $<$ Quotative particle to $+i u$ 'say')

Conjunction: shitagatte ('accordingly' $<$ Gerundive form of verb shitagau 'follow'), etc.

Determiner: aru ('a certain'; < aru 'exist'), etc.

Modality gram: - $k a$ mo shire nai ('it may be that' < Question particle $k a+$ Focus Particle mo + shiru 'know' + nai 'Neg'), etc.

Postposition: -ni tsuite ${ }^{19}$ ('concerning' $<$ Locative particle $n i+$ Gerundive form of tsuku 'become attached'), etc.

Figure 8. Grams Involving Grammaticalized Verbs in Modern Japanese

Another area of Japanese grammar where grammaticalization is crucially relevant involves semantically bleached nouns with very general meaning, which are traditionally called "keishiki meishi" (lit.

19 Japanese and Korean have a number of postpositions involving grammaticalized verbs, referred to as "extended particle phrases" by Martin (1992: 194). Readers are referred to Takahashi (1994) for a detailed description of grammatical constructions involving grammaticalized verbs in Japanese, and to Matsumoto (1995b) for a cognitive linguistic analysis of postpositions involving grammaticalized verbs. 
formal nouns) in Japanese grammar. ${ }^{20}$ The following figure illustrates a subset of grammatical constructions involving grammaticalized nouns:

Aspect gram: -tokoro da (Progressive/Anterior < tokoro 'place' + Copula $d a$ ), etc.

Complementizer: koto ( $<$ 'matter, thing'), tokoro ( $<$ 'place')

Conjunctive Particle: -mono no (Concessive $<$ mono 'thing' + Genitive no), etc.

Conjunction: tokoroga ('however' $<$ tokoro 'place' + Nominative particle $g a$ ), etc.

Modality gram: -yoo da (Epistemic Probability < Old Japanese -yoo nari; yoo 'appearance' + Copula nari), etc.

Figure 9. Grams Involving Grammaticalized Nouns ${ }^{21}$

Though Figures 8 and 9 are not exhaustive, they are sufficient to demonstrate that grammaticalization plays a very important role in shaping the grammatical structure of Japanese in both verbal and nominal domains.

The grammar of Japanese thus offers a variety of grammatical categories and constructions in which to test the grammaticalization hypotheses proposed in EOG. Take for example various mechanisms of semantic change discussed in Chapter 8 of EOG, e.g. Inference, Metaphor, Generalization, etc. It seems to be certainly worthwhile to inquire what kinds of mechanism of semantic change are at work in the grammaticalization process of Japanese, an area of research which has not been fully explored in the previous Japanese linguistic studies. ${ }^{22}$

I would like to conclude this section by emphasizing once again the importance of "re"-viewing Japanese grammar from the perspective of grammaticalization espoused in EOG, specifically form-meaning interaction in diachrony and the actual mechanisms of semantic change.

20 Readers are referred to works by Hideo Teramura (e.g. Teramura (1992)) and Kanae Sakuma (e.g. Sakuma (1983)) for the important role played by grammaticalized nouns in the grammar of Japanese.

21 Readers are referred to Horie (forthcoming) for a cognitive linguistic analysis of grammaticalization of overt nominalizers such as tokoro, koto and no.

22 Except a series of works by Yo Matsumoto (e.g. Matsumoto (1988, 1995b)). 


\section{Conclusion}

In this article, I have critically examined some of the major hypotheses on the development of Tense-Aspect and Modality grams presented in EOG in light of data from Japanese. I have also pointed out some possible areas of research in the grammar of Japanese where the findings of EOG can be profitably applied and tested.

EOG opens up the possibility of investigating grammaticalization patterns of particular languages, including Japanese, from the perspective of diachronic form-meaning interaction. EOG is highly recommended for anyone working on the structure and history of the Japanese language, including those working in the field of Japanese linguistics, as well as for general linguists interested in comparing languages from a synchronic and/or a diachronic perspective.

Finally I would like to say a word on EOG's "Preface and Acknowledgment." This small section of the book tells us how this book developed out of the original research project by Bybee, later joined by Perkins and Pagliuca, aided and supported by numerous scholars, contributors and organizations. It gives us a good idea what a cross-linguistic research project of this scale would entail, e.g. financial support (occasionally "not in the full amount requested" (EOG: xvi) - sounds familiar?), close collaboration among researchers, assistance and consultation offered by academic colleagues, and above all, a firm determination to complete the project. It is a touching story that any hard-working linguist would empathize with.

\section{REFERENCES}

Bolinger, Dwight (1977) Meaning and Form, Longman, London.

Dryer, Matthew S. (1989) "Large Linguistic Areas and Language Sampling," Studies in Language 13, 257-292.

Dryer, Matthews S. (1992) "The Greenbergian Word Order Correlations," Language 68, 81-138.

Givón, Talmy (1980) "The Binding Hierarchy and the Typology of Complements," Studies in Language 4, 333-377.

Givón, Talmy (1990) Syntax II, John Benjamins, Amsterdam.

Haiman, John (1983) "Iconic and Economic Motivation," Language 59, 781-819.

Haiman, John (1985) Natural Syntax, Cambridge University Press, Cambridge. 
Hawkins, John A. (1994) A Performance Theory of Order and Constituency, Cambridge University Press, Cambridge.

Heine, Bernd, Ulrike Claudi, and Friederike Hünnemeyer (1991), Grammaticalization: A Conceptual Framework, University of Chicago Press, Chicago.

Hopper, Paul J. and Elizabeth Closs Traugott (1993), Grammaticalization, Cambridge University Press, Cambridge.

Horie, Kaoru (1995) "Gengo Ruikeiron I (Linguistic Typology I)," Kaigai Gengogaku Joohoo 8 (Current Trends in Overseas Linguistics 8), ed. by Hinds Morioka and Yasuhiko Kato, 75-92, Taishukan, Tokyo.

Horie, Kaoru (Forthcoming) "The Cognitive Nature of Grammaticalization of Overt Nominalizers in Modern Japanese," Nihon Edward Sapir Kyokai Kenkyu Nenpoo (Bulletin of the Edward Sapir Society of Japan) 11, 1-10.

Hotta, Yoji (1969), "Mu (N)," Joshi Jodooshi Shoosetsu (A Reference Grammar of Particles and Auxiliaries), ed. by Akira, Matsumura, 155-165, Gakutosha, Tokyo.

Martin, Samuel E. (1992) A Reference Grammar of Korean, Tuttle, Tokyo.

Masuoka, Takashi (1991) Modaritii no Bunpoo (Grammar of Modality), Kurosio, Tokyo.

Matsumura, Akira, ed. (1969) Joshi Jodooshi Shoosetsu (A Reference Grammar of Particles and Auxiliaries), Gakutosha, Tokyo.

Matsumoto, Yo (1988) "From Bound Grammatical Markers to Free Discourse Markers: History of Some Japanese Connectives," BLS 14, 340-351.

Matsumoto, Yo (1995a) "Gengo ruikeiron II (Linguistic Typology II)," Kaigai Gengogaku Joohoo 8 (Current Trends in Overseas Linguistics 8), ed. by Hinds Morioka and Yasuhiko Kato, 93-101, Taishukan, Tokyo.

Matsumoto, Yo (1995b) "Semantic Constraint on Grammaticalization: Evidence from Japanese Postpositions and Conjunctions," paper read at the 4th International Cognitive Linguistics Association, University of New Mexico, USA.

Mikami, Akira (1972) Gendai Gohoo Josetsu (Introduction to Modern Japanese Grammar), Kurosio, Tokyo.

Nichols, Johanna (1992) Linguistic Diversity in Time and Space, University of Chicago Press, Chicago.

Nitta, Yoshio (1991) Nihongo no Modaritii to Ninshoo (Modality and Person in Modern Japanese), Hituzi Syobo, Tokyo.

Nitta, Yoshio and Masuoka Takashi (1989) Nihongo no Modaritii (Modality in Modern Japanese), Kurosio, Tokyo.

Ono, Tsuyoshi (1992) "The Grammaticization of the Japanese Verbs $O k u$ and Shimau," Cognitive Linguistics 3-4, 367-390.

Ono, Susumu, Satake Akihiro, and Maeda Kingoro (1990) Iwanami Kogo Jiten Hoteiban (Iwanami Classical Japanese Dictionary, Revised Edition), Iwanami Shoten, Tokyo.

Onoe, Keisuke (1996) "Bun o Doo Mita ka: Jutsugoron no Gakushiteki Tenkai 
(How were Sentences Recognized and Defined?: A Historical Development of Theories on Predication)," Nihongogaku 15-8, 4-12.

Perkins, Revere D. (1989) "Statistical Techniques for Determining Language Sample Size," Studies in Language 13, 293-315.

Rijkhoff, Jan, Dik Bakker, Kees Hengeveld, and Peter Kahrel (1993) "A Method of Language Sampling," Studies in Language 17-1, 169-203.

Sakuma, Kanae (1983) Gendai Nihongo no Hyoogen to Gohoo (Expression and Grammar of Modern Japanese), Kurosio, Tokyo.

Sapir, Edward (1921) Language, New York, Harcourt, Brace and World.

Shibatani, Masayoshi (1984) "Koochakugo to wa Nani ka (What is agglutinating language?)," Kenkyuu Shiryoo Nihon Bunpoo 5 (Research Reference on Japanese Grammar 5), ed. by Kazuhiko Suzuki and Oki Hayashi, 34-52, Meiji Shoin, Tokyo.

Takahashi, Taro (1994) Dooshi no Kenkyuu: Dooshi no Dooshi Rashisa no Hatten to Shooshitsu (Study of Verbs: Development and Loss of Verbhood), Mugi Shobo, Tokyo.

Teramura, Hideo (1984) Nihongo no Shintakkusu to Imi II (Syntax and Semantics of Modern Japanese II), Kurosio, Tokyo.

Teramura, Hideo (1992) "Rentai Shuushoku no Shintakkusu to Imi 4 (Syntax and Semantics of Adnominal Clause Constructions 4)," Teramura Hideo Ronbunshuu I (Collected Papers by Hideo Teramura I), Kurosio, Tokyo, 297-320.

Toyama, Eiji (1959) "U, Yoo," Kokubungaku Kaishaku to Kyoozai no Kenkyuu 9-13, 129-132.

Traugott, Elizabeth Closs, and Bernd Heine (1991) Approaches to Grammaticalization, 2 vols., John Benjamins, Amsterdam.

Traugott, Elizabeth Closs, and Ekkehard König (1991) "The SemanticsPragmatics of Grammaticalization Revisited," Approaches to Grammaticalization, Volume 1, ed. by Elizabeth Closs Traugott and Bernd Heine, 189-218, John Benjamins, Amsterdam.

Yamashita, Kazuhiro (1996) "Chuusei Igo no Teiru to Tearu (Post-Medieval Teiru and Tearu)," Kokugo Kokubun 65, 39-54.

Kokusai Bunka Kenkyuka

Tohoku University

Kawauchi, Aoba-ku, Sendai-shi

Miyagi 980-77

e-mail: khorie@intcul.tohoku.ac.jp 